\title{
Exploration on Teaching Reform of Specialized Courses in Universities -- Taking the Course "Automobile Theory" As an Example
}

\author{
Ran Zhao \\ Shandong Agricultural University, Taian 271018, China. \\ 13053869179@163.com
}

\begin{abstract}
Based on the characteristics of the Automobile Theory course itself, this paper analyzes the main problems existing in the current teaching and puts forward the ideas of constructing basic knowledge framework, improving teaching methods and designing experiments based on the actual situation of the school. At the same time, it deeply analyzes the influence of different teaching methods and assessment methods on students' subjective initiative in learning, which provides guarantee for effectively improving teaching quality and teaching effect.
\end{abstract}

Keywords: Automobile theory; teaching reform; teaching methods; teaching quality.

\section{Introduction}

The setting up of specialized courses in universities is usually in the latter half of undergraduate study and it is usually a further deduction and deeper application of the content of basic courses in the earlier period, which requires students to have systematic understanding and mastery of the leading content. At the same time, at this stage, the students' learning habits and mentality have already been quite different from those of the students when they first entered the university. All of these have put forward higher requirements for teachers in teaching practice. Taking Automobile Theory as an example, this paper studies and explores the teaching reform of university major courses.

\section{The Teaching Status of Automobile Theory Course at Home and Abroad}

\subsection{The Teaching Domestic Status of Automobile Theory Course}

As a compulsory course and core course for the major of vehicle engineering and transportation, the main content of Automobile Theory covers the analysis and research of automobile's main performance such as power, fuel economy, selection of power parameters, braking, stability, smoothness and traffic ability, which plays a role of linking the past with the future in the setting of the entire professional curriculum. At the same time, it is also one of the important courses for postgraduate students. The importance of the course is self - evident, but the teaching effect is not very ideal in actual teaching. The main reasons include the following aspects.

The automobile theory is comprehensive, which covers a wide range of contents, and requires a high mastery of the basic courses of the leading specialty. In the learning process of Automobile Theory, some advanced mathematics, theoretical mechanics, mechanical principles, material mechanics, automobile construction and engine principles need to be used. The content is complicated and systematic, which requires students to have a high degree of mastery of the basic courses of the previous specialties. However, many students do not have a good grasp of the basic knowledge of these specialties, which leads to passive learning of Automobile Theory and even to feelings of difficulty, greatly restricting the exertion of their subjective initiative so that the quality of teaching is caused to be declined [1].

The teaching method of Automobile Theory is relatively simple, and the teaching effect is not satisfactory. In the teaching of Automobile Theory, it needs to use multimedia demonstration to deepen students' understanding as its curriculum contains a large number of contents related to automobile structure and engine principles. However, ignoring the function of blackboard writing in 
teaching and blindly using multimedia make students have difficulty in focus their attentions and the teaching effect not ideal as well.

The teaching method of Automobile Theory is rigid, which is difficult to stimulate students' enthusiasm for learning this course. In the teaching process of Automobile Theory, teachers are still used to teach on the platform and students listen passively below. The vast majority of students do not have the opportunity to participate in the interaction with teachers in the whole process. The teaching process is rather dull, the enthusiasm of students in learning is not high, and the teaching effect is not very good either.

The contents of the course Automobile Theory makes too much emphasis on theory, and the combination of theory and practice is not strong enough. Also, its function of guiding practice has not been given full play [1].

\subsection{Current Situation Abroad of Teaching Automobile Theory}

Since there are different teaching plans and emphases in automobile engineering education at home and abroad, the teaching of Automobile Theory has its own characteristics in the aspects of curriculum system and teaching methods.

\subsubsection{The Existence of Differences in Curriculum System Settings}

German curriculum settings often form a fixed system and its structure is very clear. Unlike Chinese teaching, which regards automobile construction and automobile design as the other two courses, German automobile construction and automobile design knowledge are integrated into the study of Automobile Theory, which can enable students to better understand how to design automobiles and the theory of structure verification. However, the addition of knowledge of automobile construction and automobile design will cause certain damages to the curriculum system of Automobile Theory. How to reduce such damages is not very well dealt with by Germany either [2]; On the other hand, since this kind of learning about automobile construction and design is often theoretical in nature, students often only know the theory, and it is difficult for them to truly understand the real construction and design knowledge.

The American system is similar to German one and even more complete, but at the same time it also leads to too many knowledge points, which makes it difficult for students to accept and easily lose their subjective initiative to think about and discover problems. The structure system of the Japanese curriculum is similar to that of China, which is mainly based on pure automobile theory and performance method tests, and basically does not involve the contents of automobile structure and design, making the structure of the teaching material simple and clear and easy for students to understand and systematically summarize.

\subsubsection{Differences in Teaching Methods}

Due to differences in national conditions and culture, Automobile Theory courses are generally taught in small classes in foreign countries and at the same time are paid attention to heuristic teaching for students to stimulate their enthusiasm for learning. Meanwhile, American colleges and universities will mobilize students' subjective initiative through communication and interaction between teachers and students while teaching theories so that students can actively participate in teaching activities.

\section{The Exploration of the Curriculum Reform of Automobile Theory}

In view of the above problems, in order to stimulate students' subjective initiative in learning on the basis of the current teaching resources, we have carried out reforms in several aspects such as teaching content, teaching methods, teaching methods, practical teaching and assessment methods so as to improve the teaching quality of the courses. 


\subsection{Establishing a Framework of Professional Basic Knowledge}

According to the characteristics of Automobile Theory course, clarifying the chapter structure, refining all the knowledge points, tracing back to the original pilot course according to the content, returning the automobile structure to the automobile structure and the mechanics to the mechanics, and constructing the corresponding professional knowledge framework in different categories. In this way, the explanation can be targeted. By inspiring students to recall what they have learned in the past, it is helpful to improve the learning effect of students, especially those with poor professional foundation. For example, when the factors that affect the fuel economy are discussed, the related knowledge such as fluid mechanics, automobile construction, engine principle, material mechanics and the like will be connected in series in the form of a tree diagram in advance, which will help students better understand when explaining, and at the same time can better enable students to consolidate the old knowledge.

\subsection{Enriching the Teaching Methods}

With the progress of technology, the teaching content is constantly enriched, and the class hours of the course are relatively compressed. How to enable students to learn and master the curriculum content step by step within a limited period of time is what we need to study carefully [1]. Automobile Theory is a highly theoretical course. According to the specific teaching content, the teaching mode of combining multimedia with blackboard writing can be used in the current teaching. For example, there are a lot of stress analysis and formulas in Automobile Theory that require students to understand and master the derivation process, such as the stress analysis of automobile braking force and driving force. If the multimedia teaching is still used blindly, students will need to pay high attention in a long period of time. One is that it is difficult for students to continue their concentration, the other is that the amount of information is too large. Students do not have too much time to think and the teaching effect is not very good. At this time, the traditional blackboard writing method can be used. On one hand, it can give students more time to think and understand, let students take notes while listening along with the teacher's thinking, and cultivate students' logical thinking ability. On the other hand, it can slow down the pace, and elaborate the key and difficult points in the explanation process in detail and repeatedly in the blackboard writing, so as to deepen students' impression of this part of the content. Besides, by using the traditional teaching mode of blackboard writing, the beautiful and neat chalk words will cause strong emotional impact on students, attract students' attention, and mobilize their potential initiative to participate in learning. There are still many contents in Automobile Theory that are related to the automobile structure and engine principles and need to be displayed vividly, such as the working process of the engine and the working principle of ESP multimedia courseware can be used to demonstrate. Animation or video can be used to make some contents that are difficult to express with chalk and blackboard intuitive and understandable. Even there are some formulas that are more abstract or cannot obtain accurate results by calculation and drawing alone. For example, when the properties of vehicle stability are discussed, such as amplitudefrequency characteristics and transient response of yaw rate, MATLAB and other simulation software can be used to carry out simulation calculation, which can transform the theoretical model in the teaching material into simulation model to vividly understand the influence of braking and steering control on vehicle handling stability [3].

\subsection{Appropriately Using the Interactive Teaching Methods}

The traditional teaching method should even be called "indoctrination" teaching. The teacher teaches the class step by step according to the textbook on the platform. Students simply listen passively to the teacher's words and do not have many opportunities to express their ideas, especially for whom with poor foundation may really just sit and passively listen. The teacher also does not know how much the students understand and how much knowledge they can master. What the teacher can only do is to take the class as what the teacher has planned, so the teaching effect is hardly good. We try to use interactive teaching, which is more inclined to make students "individualized" learning, let students become the main body of teaching and stimulate students' learning enthusiasm through 
students' active participation in the teaching process. Specifically, there can be two forms. One is that teachers draw up topics in advance. For example, the topic is "the current situation and development direction of new energy vehicles at this stage". After consulting materials and discussions in groups, a student represented by the group will introduce the ideas and practices of the group in the form of reports, and other groups of students will ask some questions, which not only enlivens the classroom atmosphere, but also can train students' language organization and expression ability. The other is that students will ask questions and the class is mainly conducted by students' discussion. The teacher will guide and grasp the direction of students' discussions, and give them appropriate supplement and development. At the same time, teachers can observe the individual differences among different students in the discussion process, communicate with them frequently, and mobilize their enthusiasm in a targeted way to effectively improve students' subjective initiative in learning [4].

\subsection{Exploring Case Teaching}

Automobile Theory is so theoretical and difficult that it is very difficult for teachers to keep students' high attention all the time by blindly explaining the theory in class, which will inevitably lead to students' lack of thorough understanding of the content, let alone flexible use. In the long run, some students will be afraid of hardship and even gradually lose their interest in the course. At the same time, with the development of network technology at this stage, students are getting more and richer in resources on the internet, and the speed of accepting new knowledge is getting stronger and stronger. The pure text description in books can no longer fully mobilize students' enthusiasm for learning. Thus, case teaching method is adopted in the class, which combines the theoretical principles of the course with some phenomena and engineering examples in life with case as the main line [3]. Firstly, questions are raised about a certain phenomenon, such as the competition of the formula racing car." Why does the car turn sideways? ", this question will arouse students' interest and make them discuss with each other, which is the most important link to improve the teaching effect. The more students participate in the discussion, the more thorough the discussion will be and their abilities to analyze and solve problems will be better. At the same time, according to the specific situation during the discussion, students should be properly intervened. Students with clear thinking can guide them to deepen the problem, while students who are not active should be encouraged and urged [5]. Finally, the teacher summarizes and points out the comprehensiveness and accuracy of students' discussion, helps students to sort out and analyze the thinking of problems, and guides students to self-evaluate and think about the rationality of problems, which not only helps improve students' ability to innovate and learn independently, and enables students to understand abstract theories with vivid examples, but also enables students to fully feel the importance of theoretical knowledge learned in solving practical problems in order to increase their interest in learning.

\subsection{Appropriately Using the Retrospective Teaching and Innovative Experimental Design in Practical Teaching}

In the traditional practice teaching, it still stays on the verification test of the power, fuel economy and braking performance of the automobile. About 10 students are grouped together, and the teacher makes explanation and demonstration. In the experiment, students can think more deeply about the experiment by asking questions and can also review the textbook knowledge to verify the theory and are cultivated their abilities to integrate theory with practice. Besides, students are encouraged to carry out design experiments under the existing equipment conditions. For example, students can propose improvement designs for brakes of certain car models and they can also consult their own data, carry out their own scheme design and calculation of parameters, carry out their own practical operations and process the results, which can greatly improve students' subjective initiative in learning this course and their ability to learn and solve problems independently can also be fully exercised at the same time. 


\section{Conclusion}

As the teacher of vehicle engineering specialty, I should make up for the deficiency of traditional teaching by continuously exploring and researching, diversifying teaching methods, innovating teaching methods and methods, and stimulating students' subjective initiative in learning. More emphasis should be placed on the important role of practical ability in curriculum learning and on how to integrate theory and practice more closely in teaching. Through the further improvement of the evaluation method of curriculum assessment, the comprehensive ability of students can be evaluated more comprehensively and accurately.

\section{References}

[1]. Liu Tingting, Liu Zhongmin, et al. Discussion on Teaching Reform of Automobile Theory [J]. Education and Teaching Forum.Vol. 44 (2015) No.3, p. 96-97.

[2]. Xia Quashing, Li Keying, et al. Comparative Study of Typical Chinese and Foreign Teaching Materials on Automobile Theory [J]. China University Teaching. (2009) No.5, p. 87-90.

[3]. Wang jingyue, Chen Ke, et al. Research on Teaching Reform of Automobile Theory Course [J]. Journal of Lanzhou Institute of Education. (2016) No.4, p. 89-91.

[4]. Zhu Hong, Ma Lipping, et al. "Study on the Effect of Teaching Model of" Large Class Teaching and Small Class Discussion "[J]. China Higher Education Research.(2016) No.1, p. 42-46.

[5]. Zhang Yanshan, Chen Hai, et al. Application of Case Teaching Method in Automobile Theory Course Teaching [J]. Tian Middle School Journal.(2017) No.4, p. 154-156. 